\title{
The First Report of Clinical and Pathological Studies of Polycystic Kidney Disease in a Herrik Lamb in the Middle East
}

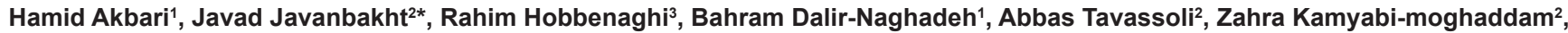 \\ Meysam Jani ${ }^{4}$, Sayyad Golami ${ }^{4}$ and Mojtaba Rajabian ${ }^{4}$ \\ ${ }^{1}$ Department of Clinical Sciences, Faculty of Veterinary Medicine, Urmia University, Urmia, Iran \\ ${ }^{2}$ Department of pathology, Faculty of Veterinary Medicine, Tehran University, Tehran, Iran \\ ${ }^{3}$ Department of pathology, Faculty of Veterinary Medicine, Urmia University, Urmia, Iran \\ ${ }^{4}$ Graduate, Faculty of Veterinary Medicine, Tehran University, Tehran, Iran
}

\begin{abstract}
In April 2012, a 1-week-old female lamb was presented for evaluation to the field service at the Teaching Hospital Center, University of Urmia School of Veterinary Medicine with a history of progressive bilateral abdominal distention since birth. Two days after birth, the animal had mental dullness, a poor growth rate comparable to a twin, and progressive bilateral abdominal distension. On physical examination, the animal was in poor body condition and had a mass palpable in the cranial ventral abdomen (The abdomen was tight, round, and painful on palpation) and also lamb was bright, low awareness and responsive. Temperature $\left(37^{\circ} \mathrm{C}\right)$, pulse (154 beats per minute), and respiration (55 breaths per minute) and weighing $3.5 \mathrm{~kg}$ were elevated. Histopathological examinations revealed that bilaterally enlarged kidneys were characterized by renal tubules at all levels of the nephron unit and extended into the cranial ventral abdomen. Glomeruli were sporadic, small and often hypoplastic or atrophic, located within a dilated Bowman's capsule. Renal cysts were usually bilateral, occurred in cortex and medulla and varied from less than $0.5 \mathrm{~mm}$ to over $5 \mathrm{~mm}$ in diameter. Cysts were lined by epithelial cells of nephron origin. Macroscopic and microscopic studies were similar to autosomal recessive polycystic kidney disease in humans and to previous reports of juvenile polycystic disorders in several animal species. Consequently, a polycystic kidney disease was diagnosed in Herrik lamb.
\end{abstract}

\section{Keywords: Congenital; Kidney; Pathology; Cyst; Lamb}

\section{Introduction}

Polycystic kidney disease (PKD) has been reported infrequently in a variety of domestic, laboratory, and wildlife species, Persian cats [1], Cairn Terriers [2], West Highland White Terriers [3], a raccoon [4], a Nubian goat [5], rats [6], mice [7], pigs [8], humans [9], African gazelles, cattel [10], sheep [11] and springbok (Antidorcas marsupialis) [12].

PKD is characterized by gradual enlargement of the kidneys because of numerous expansile cysts and eventually leads to kidney failure. Cystic renal lesions have also been produced experimentally in rats given different chemicals [13-15]. PKD, a congenital disease recognized in lambs, has not been described adequately either in terms of pathology or epidemiology. Renal cystic diseases constitute a heterogenous group of hereditary, acquired and developmental disorders. Clinical symptoms of renal disease depend on the degree of involvement of the kidneys $[16,17]$ and the widespread reduction in the functional kidney mass will usually lead to renal failure. In humans, PKD is an important cause of morbidity and mortality, being more common than other significant hereditary disorders such as sickle cell anemia, hemophilia, Huntington's chorea, and cystic fibrosis. In humans, congenital cystic lesions of the hepatic often together with kidney lesions and represent a intricate group of disorders that have been subjected to extensive clinical, pathologic and genetic studies $[18,19]$. In humans, PKD is heritable and recognized in at least 2 genetically, recognizable forms: infantile or Autosomal Recessive PKD (ARPKD) and adult or Autosomal Dominant PKD (ADPKD). Adult form is slowly progressive, often associated with a various of extrarenal manifestations and usually leads to death from renal failure in late adulthood and also infantile form is rare, often diagnosed in early infancy by massive nephromegaly, and is rapidly progressive [20]. Although ADPKD form has been classified into perinatal, neonatal, infantile and juvenile forms on the basis of age of presentation, genetic studies show all forms have an identical genetic defect, scilicet mutations of a single ARPKD gene linked to chromosome 6p2cen [2]. In domestic animals, ARPKD with hepatic cysts and fibrosis has been described in 6-week-old Cairn Terriers [3], 5-week-old West Highland White [21] and in 7-week-old crossbred Persian kittens in a family of closely-related cats 28 similar cystic renal and hepatic lesions were described in a single 3-week-old Nubian goat [22].

\section{Case Histories}

A 1-week-old female lamb was presented for evaluation to the field service at the Teaching Hospital Center, University of Urmia School of Veterinary Medicine with a history of progressive bilateral abdominal distention since birth. Two days after birth, the animal had mental dullness, a poor growth rate comparable to a twin and progressive bilateral abdominal distension.

On physical examination, the animal was in poor body condition and had a mass palpable in the cranial ventral abdomen (The abdomen was tight, round, and painful on palpation) and also lamb was bright, Low awareness and responsive. Temperature $\left(37^{\circ} \mathrm{C}\right)$, pulse $(154$ beats per minute), and respiration (55 breaths per minute) and weighing 3.5 $\mathrm{kg}$ were elevated.

*Corresponding author: Dr. Javad javanbakht, Department of Pathology, Faculty of Veterinary Medicine, Tehran University, Tehran, Iran, Tel:+989372512581; E-mail: javadpatho@yahoo.com

Received April 20, 2012; Accepted May 09, 2012; Published May 15, 2012

Citation: Akbari H, Javanbakht J, Hobbenaghi R, Dalir-Naghadeh B, Tavassoli A, et al. (2012) The First Report of Clinical and Pathological Studies of Polycystic Kidney Disease in a Herrik Lamb in the Middle East. J Bacteriol Parasitol 3:138. doi:10.4172/2155-9597.1000139

Copyright: ( 2012 Akbari $\mathrm{H}$, et al. This is an open-access article distributed unde the terms of the Creative Commons Attribution License, which permits unrestricted use, distribution, and reproduction in any medium, provided the original author and source are credited. 
Citation: Akbari H, Javanbakht J, Hobbenaghi R, Dalir-Naghadeh B, Tavassoli A, et al. (2012) The First Report of Clinical and Pathological Studies of Polycystic Kidney Disease in a Herrik Lamb in the Middle East. J Bacteriol Parasitol 3:138. doi:10.4172/2155-9597.1000139

Page 2 of 4

Because of relatively poor prognosis, the lamb was euthanatized. At necropsy, macroscopic lesions were limited to the kidneys. They were of abnormal size but indicated a grey yellow discoloration. The surface was slightly nodular and irregular and the capsule was thin, tightly adherent, and translucent, through which could be seen numerous Fluid-Filled Cysts (FIG) (Figure 9). On the external as well as one the cut surfaces, many small cysts $(0.5-5 \mathrm{~mm})$ could be seen (FIG). Both kidneys were enlarged and extended into the cranial ventral abdomen, displacing viscera dorsally; the right kidney was $15 \times 6 \times 4 \mathrm{~cm}$ and the left kidney was $15 \times 7 \times 4 \mathrm{~cm}$ and total weight of both kidneys was $925 \mathrm{~g}$ (Figure 10), that these cysts in all levels were scattered of round and small grains and the cross section of the kidney, there was no clear distinction between cortex and medulla because cysts were diffusely distributed throughout both cortex and medulla and also was not seen

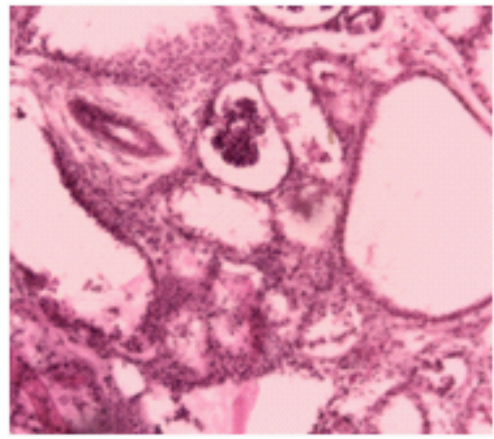

Figure 1: The number of glomeruli was greatly reduced. Those present were small and located within a dilated Bowman's capsule.

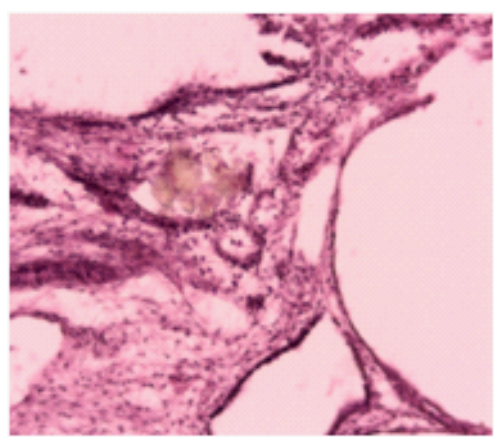

Figure 2: Dilated tubules were sporadically separated by variable amounts of expanded, loose interstitial tissue and sometimes the gray-white crystals of calcium were seen in tubules with loose embryonic interstitial tissue.

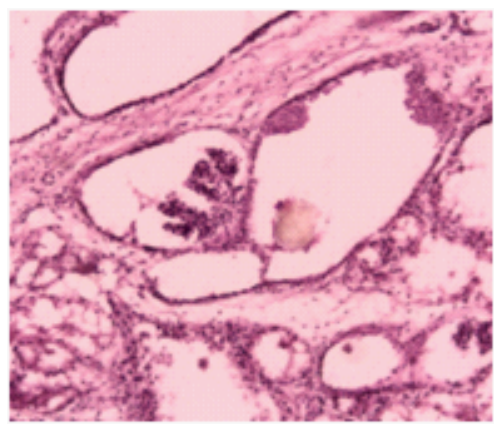

Figure 3: The number of glomeruli was greatly reduced. Those present were small and located within a dilated Bowman's capsule. even a trace of the pelvis and also the ureters, and bladder were grossly normal and there was only a small quantity of clear yellow urine in the bladder. No other abnormalities in any other organ or system were reported. Samples of kidney were fixed by immersion in neutral-buffered $10 \%$ formalin and processed routinely for microscopic analysis. Sections were stained with Haematoxylin Eosin (H\&E).

The right and left kidneys of the PCK lamb indicated identical changes. The most important lesions were found in the renal. There was severe dilatation of renal tubules at all levels of the nephron unit (Figures 5 and 8). The kidneys were contained multiple fusiform, round and cylindrical cysts. These cysts formed an irregular honeycomb of spaces that were separated by varying amounts of cellular and stromal components of the interstitium and little normal renal parenchyma was present synthesized among dilated tubules (Figure 5).

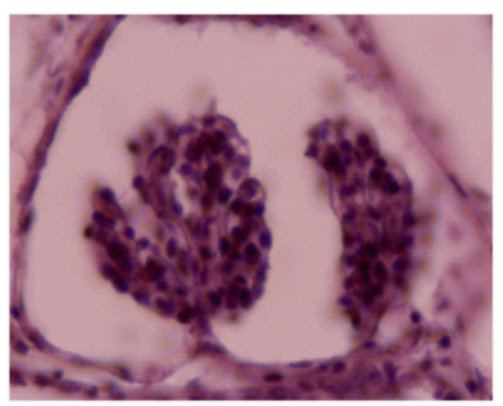

Figure 4: Glomeruli were sporadic, small, and often hypoplastic or atrophic, located within a dilated Bowman's capsule and the capsules were often continuous with dilated proximal tubules.

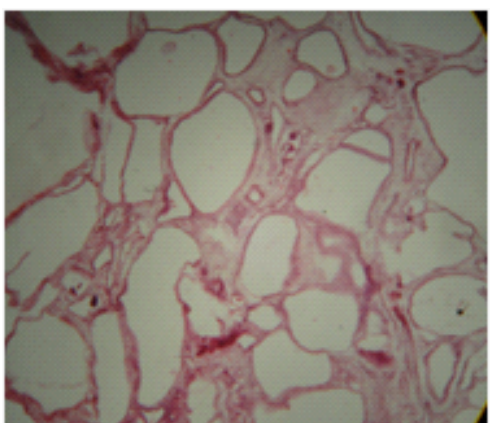

Figure 5: The cysts formed an irregular honeycomb of spaces that were separated by varying amounts of cellular and stromal components of the interstitium and little normal renal parenchyma was present synthesized among dilated tubules.

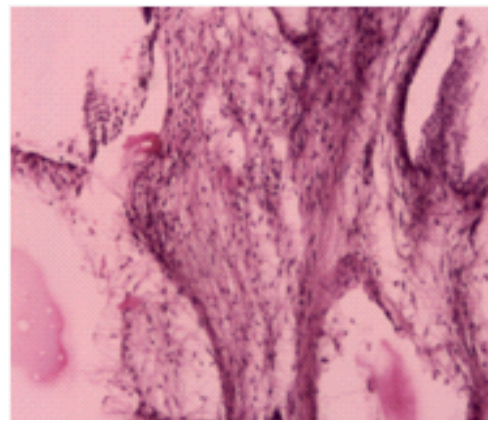

Figure 6: The corticomedullary junction was obscured. Sometimes the corticomedullary interstitium was focally edematous and contained reactive fibroblasts and edematous fibrous connective tissue. 
Citation: Akbari H, Javanbakht J, Hobbenaghi R, Dalir-Naghadeh B, Tavassoli A, et al. (2012) The First Report of Clinical and Pathological Studies of Polycystic Kidney Disease in a Herrik Lamb in the Middle East. J Bacteriol Parasitol 3:138. doi:10.4172/2155-9597.1000139

Page 3 of 4

The corticomedullary tubules were dilated and lined by low cuboidal to flattened squamous or flattened columnar epithelium (Figure 7). Most dilated tubules were empty, but some contained a homogenous or fluffy eosinophilic material. Dilated tubules were sporadically separated by variable amounts of expanded, loose interstitial tissue and sometimes the gray-white crystals of calcium were seen in tubules with loose embryonic interstitial tissue (Figures 2 and 3).

The corticomedullary junction was obscured. Sometimes the corticomedullary interstitium was focally edematous and contained reactive fibroblasts and edematous fibrous connective tissue (Varied amounts of

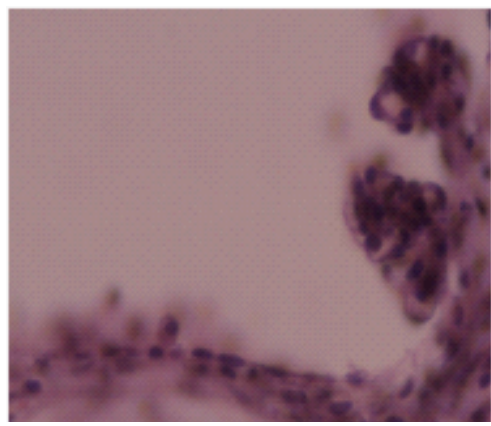

Figure 7: Glomeruli were sporadic, small, and often hypoplastic or atrophic, located within a dilated Bowman's capsule and the capsules were often continuous with dilated proximal tubules.

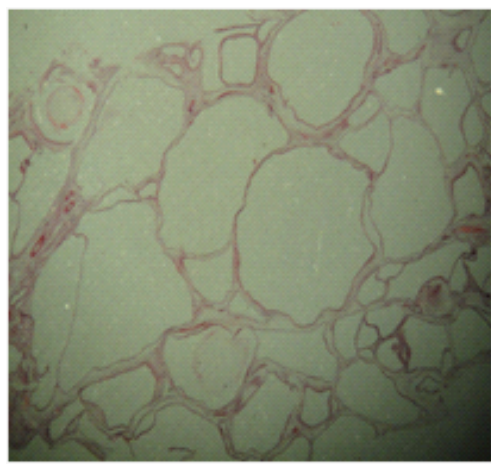

Figure 8: The right and left kidneys of the PCK lamb indicated identica changes. The most important lesions were found in the renal. There was severe dilatation of renal tubules at all levels of the nephron unit.

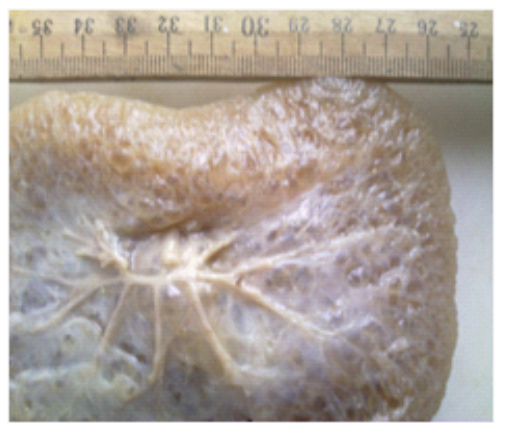

Figure 9: The surface was slightly nodular and irregular and the capsule was thin, tightly adherent, and translucent, through which could be seen numerous Fluid-Filled Cysts (FIG)

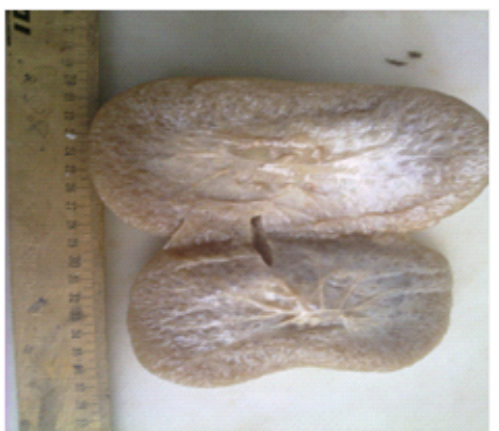

Figure 10: Both kidneys were enlarged and extended into the cranial ventral abdomen, displacing viscera dorsally.

mature fibrous connective tissue surrounded the cysts) (Figure 6). The number of glomeruli was greatly reduced. Those present were small and located within a dilated Bowman's capsule (Figures 1 and 3). Glomeruli were sporadic, small, and often hypoplastic or atrophic, located within a dilated Bowman's capsule (Figures 4 and 7) and the capsules were often continuous with dilated proximal tubules. Although the concentration of cysts was greatest in cortical areas, they extended deeply into the medullary area where many were lined by flattened epithelium more typical of that of normal collecting ducts. Microscopic examination revealed lesions uniformly distributed in the renal cortex. Sometimes cysts were seen to merge that this process was due to pressure from the cysts round.

\section{Discussion}

Cystic disease involving both the hepatic and renal was described first in 1956 [23]. Most researchers believe that polycystic disease is an inheritable disorder, in which both kidneys, that occurs in at least two major types, an adult form and an neonatal form, each with different modes of inheritance [24,25]. This polycystic disease in adolescent animals of any species most closely resembles the autosomal recessive polycystic disease complex seen in young children. Normally, the autosomal recessive form occurs early in life and is a more severe condition than that of later onset autosomal dominant forms and often compatible with the human ARPKD in that the disease manifests as stillbirths or death within the first few weeks of life, although revelation consistent with the ADPKD have also been described [26]. The cause of cystic disorders has not been specified. A common pathogenesis for all the ductular lesions is suspected [27]. Offered theories include a primary defect in epithelial cell growth and differentiation, an abnormal expression of proto-oncogenes and/or over expression of epidermal growth factor receptor, an extracellular matrix alteration and a variation in the symmetry of tubular lining cells because of imperfect tubular cell differentiation. Another possible pathogenesis for cystic lesions in kidneys could be acquired tubular cystic change and fibrosis. This may occur after interstitial nephritis associated with neonatal septicemia $[13,28,29]$. The lamb described in this case report was from a Herrick sheep and was born with a twin that died from unknown causes at birth. Histopathological survey of a biopsy specimen is most helpful to obtain a definitive diagnosis $[30,31]$ in domestic animals, classification of renal cysts is simple because this type of kidney disease has not been very well studied $[32,33]$. This case report supports that opinion, because of the glomerular lesions. Microdissection examination of polycystic kidneys in man have shown that most of the cysts are dilatation of tubules $[34,35]$. Few cases have been reported in which the cysts result from the dilatation of the glomeruli. The glomerular origin of the cysts 
Citation: Akbari H, Javanbakht J, Hobbenaghi R, Dalir-Naghadeh B, Tavassoli A, et al. (2012) The First Report of Clinical and Pathological Studies of Polycystic Kidney Disease in a Herrik Lamb in the Middle East. J Bacteriol Parasitol 3:138. doi:10.4172/2155-9597.1000139

is demonstrated by the regular and roundish shape of the cysts and significantly by the presence of the glomerular tuft in most of them. In the present case report, cystic dilations were present in the renal tubules. Renal tubular ectasia was most pronounced in the distal convoluted tubules and collecting ducts. Most reports of congenital polycystic disorders (abnormalities) in both humans and animals often have variable involvement of kidney tubules, most specially the collecting tubules $[36,19]$. Based on the morphology of the cystic lesions and the age of onset of clinical signs, the lamb described in this report has some features that are similar to those in previous reports of adolescent polycystic disease in humans and other animals. Whether this disease has a heritable component could not be accurately determined. Macroscopic and microscopic studies were similar to autosomal recessive polycystic kidney disease in humans and to previous reports of juvenile polycystic disorders in several animal species.

\section{References}

1. Biller DS, DiBartola SP, Eaton KA, Pflueger S, Wellman ML, et al. (1996) Inheritance of polycystic kidney disease in Persian cats. J Hered 87: 1-5.

2. McKenna SC, Carpenter JL (1980) Polycystic disease of the kidney and liver in the Cairn terrier. Vet Pathol 17: 436-442.

3. McAloose D, Casal M, Patterson DF, Dambach DM (1998) Polycystic kidney and liver disease in tworelated West Highland-White Terrier litters. Vet Pathol 35: $77-81$.

4. Hamir AN, Klein L (1996) Polycystic kidney disease in a raccoon (Procyon lotor). J Wildl Dis 32: 674-677.

5. Krotec K, Meyer BS, Freeman W, Hamir AN (1996) Congenital cystic disease of the liver, pancreas and kidney in a nubian goat (Capra hircus). Vet Pathol 33: $708-710$

6. Cowley BD Jr, Gudapaty S, Kraybill AL, Barash BD, Harding MA, et al. (1993) Autosomal-dominant polycystic kidney disease inthe rat. Kidney Int 43: 522534.

7. Schieren G, Pey R, Bach J, Hafner M, Gretz N (1996) Murine models of polycystic kidney disease. Nephrol Dial Transplant 16: 38-45.

8. Webster WR, Summers PM (1978) Congenital polycystic kidney and liver syndrome in piglets. Aust Vet J 54: 451

9. Dalgaard OZ (1957) Bilateral polycystic disease of the kidneys: a follow-up of two-hundred and eightyfour patients and their families. Acta Med Scand Suppl 328: 1-255.

10. Ushigaki K, Uchida K, Murakami T, Yamaguchi R, Tateyama S (1999) Multicystic renal dysplasia in a Japanese Black bull. J Vet Med Sci 61: 839-842.

11. Dennis SM (1979) Urogenital defects in sheep. Vet Rec 105: 344-347.

12. Iverson WO, Fetterman GH, Jacobson ER, Olsen JH, Senior DF, et al. (1982) Polycystic kidney and liver disease in springbok. I. Morphology of the lesions. Kidney Int 22: 146-155

13. Goodman T, Grice HC, Becking GC, Salem FA (1970) A cystic nephropathy induced by nordhydroguaiarectic acid in the rat: light and electron microscopic investigation. Lab Invest 23: 93-107.

14. Caputo CA (1980) Polycystic kidney disease in a cat. Feline Pract 10: 36-40.

15. Evan AP, Gardner KD Jr. (1976) Comparison of human polycystic and medullary kidney cystic kidney disease with diphenylamine induced cystic disease. Lab Invest 35: 93-101.

16. Vlachos J, Tsakraklidis V (1967) Glomerular cyst. An unusual variety of polycystic kidneys. Report of two cases. Am J Dis Child 114: 379-384.

17. Gardner KD Jr, Evan AP (1984) Cystic kidneys: an enigma evolves. Am J Kidney Dis 3: 403-413.

18. Osborne CA, Low DG, Finco DR (1972) Congenital and inherited renal disease. W.B. Saunders, Philadelphia.

19. Summerfield JA, Nagafuchi Y, Sherlock S, Cadafalch J, Scheuer PJ (1986) Hepatobiliary fibropolycystic diseases-aclinical and histological review of 51 patients. J Hepatol 2: 141-156.
20. Zerres K, Rudnik-Schöneborn S, Senderek J, Eggermann T, Bergmann C (2003) Autosomal recessive polycystic kidney disease. J Nephrol 16: 453-458.

21. Sessa A, Meroni M, Righetti M, Battini G, Maglio A, et al. (2001) Autosoma recessive polycystic kidney disease. Contrib Nephrol 136:50-56.

22. Crowell WA, Hubbell JJ, Riley JC (1979) Polycystic renal disease in related cats. J Am Vet Med Assoc 175: 286-288.

23. Bristowe $F$ (1856) Cystic disease of the liver associated with similar disease of the kidneys. Trans Trans Pathol Soc Lond 7235-7237.

24. Bernstein JA (1976) Classification of renal cysts. John Wiley \& Sons, New York

25. Blyth H, Ockenden BG (1971) Polycystic diseases of kidney and liver presenting in childhood. J Med Genet 8: 257-284.

26. Yoder BK, Richards WG, Sommardahl C, Sweeney WE, Michaud EJ, et al (1997) Differential rescue of the renal and hepatic disease in an autosomal recessive polycystic kidney disease mouse mutant. A new model to study the liver lesion. Am J Pathol 150: 2231-2241.

27. Crocker JF, Brown DM, Vernier RL (1971) Developmental defects of the kidney: a review of renal development and experimental studies of maldevelopment Pediatr Clin North Am 18: 355-376.

28. Carone JA, Bacallao R, Kanwar YS (1994) Biology of disease: biology of polycystic kidney disease. Lab Invest 70:437-448.

29. Fish EM, Molitoris BA (1994) Alterations in epithelial polarity and the pathogenesis of disease states. N Eng J Med 330: 1580-1588.

30. Finco DR, Osborne CA, Low DG (1975) Physiology and pathophysiology of renal failure. W.B. Saunders, Philadelphia.

31. Osathanondh V, Potter EL (1964) Pathogenesis of polycystic kidneys: Historical Survey. Arch Pathol 77: 459-465.

32. Smith HAS, Jones TC, Hunt RD (1974) Veterinary pathology. (4thedn), Lea \& Febiger, Philadelphia.

33. Darmady EM, Offer J, Woodhouse MA (1970) Toxic metabolic defect in polycystic disease of kidney. Evidence from macroscopic studies. Lancet 1: 547-550.

34. Ishak KG, Sharp HL (1994) Developmental abnormalities and liver disease in children. Churchill Livingstone, New York, NY.

35. Vargas L, Friederici HH, Maibenco HC (1970) Corticol sponge kidneys induced in rats byalloscan. Diabetes 19: 33-34.

36. Reindel J, Mullaney T, Matzat P (1988) Polycystic disease of neonatal piglets Lab Invest 58: 76. 